\title{
EFEKTIVITAS MODEL PEMBELAJARAN PROJECT BASED LEARNING TERHADAP HASIL BELAJAR MATEMATIKA SEKOLAH DASAR
}

\author{
Astria Ayu Ramadianti \\ Program Studi Pendidikan Dasar, Program Pascasarjana, Universitas Negeri Medan \\ Email: Astriria55@gmail.com
}

\begin{abstract}
ABSTRAK
Tujuan dari penelitian ini adalah untuk menganalisis kembali penggunaan model pembelajaran Project Based Learning dalam meningkatkan hasil belajar pada mata pelajaran Matematika. Metode penelitian adalah meta-analisis. Data dikumpulkan dengan menelusuri artikel, jurnal elektronik, dan esai menggunakan "Model pembelajaran Project Based Learning", "Hasil belajar", dan "Studi Matematika Pendidikan Dasar". Hasil pencarian menunjukkan bahwa ada 10 artikel, jurnal elektronik, dan esai tetapi hanya 5 artikel yang relevan, jurnal elektronik, dan esai. Data dianalisis menggunakan analisis deskriptif kuantitatif. Hasil analisis menunjukkan bahwa model pembelajaran Project Based Learning dapat meningkatkan hasil belajar siswa dari yang terendah 11,30\% sampai yang tertinggi 37,48\% dengan rata-rata sebesar $24,72 \%$.
\end{abstract}

Kata kunci: Model pembelajaran Project Based Learning, Hasil belajar, Meta-analisis.

\begin{abstract}
The purpose of this research was to re-analyze the use of Project Based Learning model in increasing the learning outcome in mathematics studies subject. The research method was meta-analysis. The data was collected by browsing article, electronic journals, and essay using "Project Based Learning model". "learning outcomes", and "Mathematics Studies of Primary Education". The searching result showed that there were 10 articles, electronic journals, and essay but only 5 relevant articles, electronic journals, and essay. The data were analyzed using quanitative descriptive analysis. The analysis result showed that project based learning model could improve student's learning from the lowest $11,30 \%$ to the highest $37,48 \%$ and the mean was $24,72 \%$.
\end{abstract}

Keywords: Project Based Learning model, Learning outcomes, meta-analysis.

\section{PENDAHULUAN}

Pendidikan merupakan suatu sektor yang memperoleh banyak pengaruh dari perkembangan ilmu pengetahuan dan teknologi. Pendidikan memegang peranan penting dalam usaha meningkatkan kualitas sumber daya manusia di masa yang akan datang yang pada akhirnya bertujuan untuk menumbuhkan nilai-nilai yang baik bagi setiap individu secara terencana. Pendidikan juga dapat diartikan pula sebagai proses untuk 
mengembangkan kemampuan diri sendiri atau individu yang akan dipergunakan dalam kehidupan bermasyarakat (Musanna, dkk., 2017).

Pembelajaran pada anak sekolah dasar merupakan tahapan pembelajaran yang bersifat operasional konkret, dimana proses belajar siswa seharusnya berinteraksi dengan benda atau peristiwa real. Untuk itu khususnya dalam pembelajaran matematika di SD suatu pembelajaran harus menekankan pada pembelajaran langsung guna mengembangkan kompetensi yang dimiliki, agar anak mampu memahami konsep matematika melalui Learning by doing.

Dalam menyampaikan materi pembelajaran, guru dituntut untuk menggunakan alat bantu yang dapat mempermudah siswa dalam memahami materi sehingga dalam pelaksanaannya guru harus mampu untuk membantu siswa dalam memahami materi matematika melalui model pembelajarran, media dan alat peraga tertentu (Wardani, dkk., 2019).

Berdasarkan pengamatan Solekhah (2018) di salah satu SD Negeri Kecamatan Tuntang terlihat bahwa sebagian peserta didik cepat merasa bosan saat pembelajaran berlangsung. Hal ini dikarenakan saat pembelajaran belum menggunakan model pembelajaran yang menuntut siswa aktif dan kurang dalam menggunakan media-media yang konkret. Untuk itu diperlukannya suatu pembahuruan atau inovasi pembelajaran berupa model pembelajaran yang dapat mengaktifkan siswa dalam proses kegiatan belajar mengajar.

Silberman dalam Relia (2012) menyatakan Guru yang baik adalah guru yang dapat membangun keaktifan siswa selama proses belajar. Keaktifan siswa dapat dibangun dengan berbagai cara salah satunya adalah dengan menerapkan model pembelajaran yang aktif dan inovatif.

Salah satu model pembelajaran yang dapat mengaktifkan siswa dalam pembelajaran adalah model pembelajaran Project Based Learning. Model pembelaajran Project Based Learning merupakan model pembelajaran yang bersifat menyenangkan karena diharapkan dapat merubah cara belajar peserta didik secara mandiri dengan meningkatkan motivasi belajar, meningkatkan kreativitas peserta didik dalam berkarya, memunculkan ide-ide kreatif serta melatih berpikir kritis, dalam menyikapi suatu masalah yang dihadapi di dunia nyata (Nugraha dkk., 2018).

Menurut penelitian terdahulu yang dilakukan oleh Ardianti dkk. (2017) menyatakan bahwa penerapan model project based learning sangat mendukung kreativitas peserta didik. Hal tersebut juga dapat dilihat bahwa sebanyak 88,9\% peserta didik kelompok eksperimen memiliki inisiatif dalam pembuatan produk yang berdampak positif terhadap peningkatan kreativitas peserta didik.

Hal senada juga diungkapkan oleh Hapsari dkk. (2018) yang mengemukakan bahwa motivasi belajar peserta didik dalam pembelajaran matematika dapat ditingkatkan dengan menerapkan model project based learning ( $\mathrm{PjBL})$. $\mathrm{Hal}$ tersebut ditunjukkan oleh hasil angket yang menunjukkan pada persentase pada siklus 1 sebesar $75 \%$ dan mengalami peningkatan pada siklus dua menjadi $83 \%$. Selain itu project based learning 
memberikan dampak positif bagi guru dan peserta didik, antara lain kreativitas peserta didik terbangun dengan adanya proyek yang harus mereka kerjakan.

$$
\text { Pada penggunaan model }
$$

pembelajaran Project Based Learning membawa banyak pengaruh, salah satu contoh pada hasil atau output belajar Matematika siswa pada tingkat sekolah dasar. Hasil tersebut dapat dilihat dari beberapa penelitian dan eksperimen yang telah dilakukan. Banyak penelitian dan eksperimen yang telah membuktikan bahwa adanya peningkatan hasil belajar setelah menggunakan model pembelajaran Project Based Learning.

Tasc1 (2015) dalam penelitiannya yang berjudul Project Based Learning from Elementary School to College, Tool: Architecture menyatakan bahwa "Project based learning approach affected academic achievement, learning permanence and learning functionality in a positive way" yaitu pendekatan pembelajaran berbasis proyek berpengaruh pada prestasi akademik, keberlangsungan belajar dan fungsionalitas belajar ke arah yang positif.

$$
\text { Bagi pendidik, model }
$$

pembelajaran berbasis proyek seharusnya terus ditingkatkan dan diaplikasikan pada proses pembelajaran matematika atau dijadikan sebagai salah satu model pembelajaran pengganti yang efisien (Melinda \& Zainil, 2020).

Berdasarkan uraian tersebut, maka fokus penelitian ini yaitu apakah penggunaan model pembelajaran Project Based Learning dapat meningkatkan hasil belajar matematika.

\section{METODE PENELITIAN}

Metode penelitian ini menggunakan jenis penelitian meta analisis. Meta analisis merupakan metode telaah sistematik yang disertai teknik statistik untuk menghitung kesimpulan beberapa hasil penelitian (Fahrezi dkk., 2020). Pengumpulan data dilakukan dengan menelusuri jurnal online, repository, dan google scholar atau lebih dikenal dengan google cendikia. Kata kunci dalam penelusuran adalah "Project Based Learning dan "Hasil belajar".

Dari hasil penulusuran diperoleh 10 artikel kemudian diambil 5 artikel yang relevan yang sudah diterbitkan oleh jurnal online. Teknik pengumpulan data dilakukan dengan penggunakan teknik dokumentasi. Dokumen tertulis yang digunakan berupa artikel, jurnal elektronik, dan skripsi. Artikel, jurnal dan skripsi yang diambil juga harus memenuhi kriteria penelitian yaitu pembahasan model pembelajaran Project Based Learning dan hasil belajar Matematika pada tingkat Sekolah Dasar yang relevan dengan pembelajaran Matematika, dan adanya data sebelum menggunakan model pembelajaran Project Based Learning dan sesudah menggunakan model pembelajaran Project Based Learning dalam bentuk skor nilai. Teknik analisis data yang digunakan adalah deskriptif kuantitatif.

Teknik analisis yang dilakukan menggunakan cara perbandingan antara selisih skor nilai sebelum menerapkan model pembelajaran Project Based Learning dan sesudah menerapkan model pembelajaran Project Based Learning. Setelah itu, dibagi dengan skor sebelum penerapan model pembelajaran Project 
Based Learning (dalam bentuk \%) untuk mengetahui presentase peningkatan hasil belajar Matematika siswa tingkat Sekolah Dasar.

\section{HASIL PENELITIAN DAN PEMBA- HASAN}

Hasil penelitian yang diikutkan dalam penelitian metaanalisis ini adalah:

1. Implementasi Model Pembelajaran Project Based Learning (PjBL) Pada Pelajaran Matematika.

2. Implementasi Pembelajaran Berbasis Proyek untuk Meningkatkan Hasil Belajar Siswa pada Mata Pelajaran Matematika di SD Negeri Pinedapa.

3. Penerapan Model Pembelajaran Project Based Learning untuk Meningkatkan Hasil Belajar Matematika Kelas II SD.

4. The Implementation Of Project Based Learning Model On Improving Mathematics Learning Outcomes Of The Fifth Grade Students At 018 Primary School Sungai Keranji.

5. Upaya Peningkatan Hasil Belajar Matematika Melalui Model Project Based Learning Siswa Kelas V SD.

Berdasarkan hasil analisis pada Tabel 1 tersebut dapat dilihat bahwa model pembelajaran Project Based Learning bisa meningkatkan hasil belajar matematika, karena terlihat dari penelitian relevan sebelumnya pada point 1 sampai 5. hal tersebut sesuai dengan penelitian yang akan dikaji berikut ini yaitu peningkatan dapat dilihat dari hasil belajar yang terendah $11,30 \%$ sampai yang tertinggi $37,48 \%$ dengan rata-rata sebesar $24,72 \%$. Hasil belajar rata-rata sebelum menggunakan model pembelajaran Project Based Learning dan sesudah menggunakan model pembelajaran Project Based Learning mengalami kenaikan yang signifikan yaitu sebesar $24,72 \%$.

Tabel 1. Hasil Analisis Model Pembelajaran Project Based Learning Terhadap Persentase Peningkatan Hasil Belajar Matematika

\begin{tabular}{|c|c|c|c|c|}
\hline \multirow{2}{*}{$\begin{array}{l}\text { Penel } \\
\text { itian }\end{array}$} & \multicolumn{4}{|c|}{ Peningkatan hasil belajar } \\
\hline & $\begin{array}{l}\text { Pre } \\
\text { Test }\end{array}$ & $\begin{array}{l}\text { Post } \\
\text { Test }\end{array}$ & Gain & $\begin{array}{c}\text { Gain } \\
(\%)\end{array}$ \\
\hline 1. & 70,74 & 78,74 & 8,00 & 11,30 \\
\hline 2. & 66,11 & 86,13 & 20,02 & 30,28 \\
\hline 3. & 68,23 & 83,86 & 15,63 & 22,91 \\
\hline 4. & 69,41 & 84,91 & 15,00 & 21,61 \\
\hline 5. & 62,70 & 86,20 & 23,50 & 37,48 \\
\hline $\begin{array}{c}\text { Rata- } \\
\text { rata }\end{array}$ & 67,44 & 83,97 & 16,43 & 24,72 \\
\hline
\end{tabular}

Tabel 2. Paired Samples Statistics

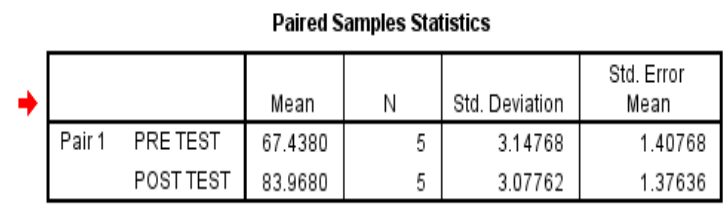

Berdasarkan Tabel 2 menunjukkan bahwa penggunakan model pembelajaraan Project Based Learning dapat meningkatkan hasil belajar Matematika dengan nilai rata-rata 67,4380 menjadi 83,9680 . 
Tabel 3. Paired Samples Correlations

Paired Samples Correlations
\begin{tabular}{|ll|r|r|c|}
\hline & \multicolumn{1}{|c|}{$\mathrm{N}$} & Correlation & \multicolumn{1}{c|}{ Sig. } \\
\hline Pair 1 & PRE TEST \& POST TEST & 5 & -.747 & .147 \\
\hline
\end{tabular}

Tabel 3 di atas menunjukkan ada atau tidaknya korelasi antara pre test dan post test. Karena nilai signifikan didapat 0,147 > 0,05 maka mengindikasikan tidak ada hubungan antara pre test dan post test.

Tabel 4. Paired Samples Test

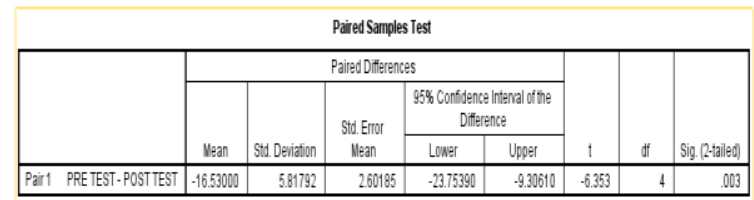

Dari Tabel 4 tampak bahwa nilai Sig. (2-tailed) $(0,003)<\alpha(0,05)$, Jadi dapat disimpulkan bahwa terdapat perbedaan yang signifikan terhadap hasil belajar matematika siswa sebelum dan sesudah pembelajaran menggunakan model pembelajaran Project Based Learning.

Berdasarkan hasil analisa penelitian dapat kita lihat bahwa penggunaan model pembelajaran Project Based Learning dari masing-masing penelitian bisa meningkatkan hasil belajar siswa. Peningkatan hasil belajar yang ada pada masing-masing penelitian memeiliki tingkat presentase yang berbeda-beda. Presentase yang dimiliki juga beragam mulai dari yang rendah, cukup, dan tinggi. Hal tersebut terpengaruh oleh beberapa faktor, baik faktor internal siswa maupun faktor eksternal siswa. Faktor internal atau faktor dari dalam individu, misalnya kemempuan, minat, bakat, dan sebagainnya. Faktor eksternal atau faktor dari luar individu, misalnya keluarga, lingkungan, waktu, sekolah, letak sekolah, kondisi sekolah, dan subjek penelitian.

\section{KESIMPULAN}

Berdasarkan hasil analisa model pembelajaran Project Based Learning, dapat ditarik kesimpulan bahwa:

1. Model pembelajaran Project Based Learning mampu meningkatkan hasil belajar matematika SD.

2. Hasil belajar siswa mulai dari yang terendah $11,30 \%$. sampai yang tertinggi $37,48 \%$ dengan rata-rata sebesar $24,72 \%$.

Saran bagi penelitian selanjutnya supaya dapat menggunakan artikel sumber lainnya dengan jumlah yang lebih banyak dan relevan. Diharapkan dalam penelitian selanjutntya peneliti mampu lebih ketat dalam menyeleksi da memilih hasil penelitian yang digunakan dalam penelitian meta-analisis, serta penggunaan metode statistik perlu diperhatikan agar hasil dari meta-analisis yang diperoleh lebih akurat.

\section{DAFTAR PUSTAKA}

Ardianti, S. D., Pratiwi, I. A., \& Kanzunnudin, M. (2017). Implementasi Project Based Learning (PjBL) Berpendekatan Science Edutainment Terhadap Kreativitas Peserta Didik. Refleksi Edukatika: Jurnal Ilmiah Kependidikan, 7(2), 145-150. 
https://doi.org/10.24176/re.v7i2.1225

Fahrezi, I., Taufiq, M., Akhwani, A., \& Nafia'ah, N. (2020). Meta-Analisis Pengaruh Model Pembelajaran Project Based Learning Terhadap Hasil Belajar Siswa Pada Mata Pelajaran IPA Sekolah Dasar. Jurnal Ilmiah Pendidikan Profesi Guru, 3(3), 408.

https://doi.org/10.23887/jippg.v3i3.2 8081

Hapsari, D. I., Airlanda, G. S., Profesi, P., Universitas, G., \& Satya, K. (2018). Penerapan Project Based Learning Untuk Meningkatkan Motivasi Belajar Matematika Peserta Didik Kelas V Implementation of Project Based Learnng To Improve Mathematics Learning Motivation the. Jurnal Pendidikan Dasar Islam, 5(2), 154-161.

Solekhah, Iis. (2018). Penerapan Model Pembelajaran Project Based Learning Untuk Meningkatkan Hasil Belajar Matematika Kelas II SD. Jurnal Didaktika Dwija Indria (SOLO), 6(2), 1-7.

Melinda, V., \& Zainil, M. (2020).

Penerapan Model Project Based Learning untuk Meningkatkan Kemampuan Komunikasi Matematis Siswa Sekolah Dasar (Studi Literatur). 4, 1526-1539.

Musanna, A., Wibowo, U. B., \& Hastutiningsih, A. D. (2017). Indigenisasi Pendidikan: Rasionalitas Revitalisasi Praksis Pendidikan Ki Hadjar Dewantara. Jurnal Pendidikan Dan Kebudayaan, 2(1), 117. https://doi.org/10.24832/jpnk.v2i1.52 9
Nugraha, A. R., Kristin, F., \& Anugraheni, I. (2018). Penerapan Model Pembelajaran Project Based Learning (Pjbl) Untuk Meningkatkan Kreativitas Dan Hasil Belajar IPA Pada Siswa Kelas 5 SD. Kalam Cendekia.

https://core.ac.uk/download/pdf/3047 19064.pdf

Relia, L. (2012). Keterkaitan antara Lembar Kerja Peserta Didik (LKPD) Matematika dengan Model Pembelajaran Kreatif, Inovatif , dan Produktif (KIP). PRISMA (Prosiding Seminar Nasional Matematika), 97103.

Tasc1, B. G. (2015). Project Based Learning from Elementary School to College, Tool: Architecture. Procedia - Social and Behavioral Sciences, 186, 770-775. https://doi.org/10.1016/j.sbspro.2015 .04 .130

Wardani, D. K., \& Wijayanti, A. (2019). Pengaruh Model Pembelajaran Project Based Learning terhadap Hasil Belajar Matematika. 207-213.

98 Efektivitas Model Pembelajaran Project Based Learning Terhadap Hasil Belajar Matematika Sekolah Dasar Astria Ayu Ramadianti 